\title{
Evaluation of Public Transport: A Case Study of Hyderabad Sindh Pakistan
}

\author{
* Abdul Ghafar \\ ** Zulfiqar Ali Lashari \\ *** Shahbaz Khan Samoo
}

\begin{abstract}
The spatial and economic growth of cities and regions is heavily influenced by transportation. A better knowledge of public transportation will help to clarify the positions of the public and private sectors, as well as recognize the critical government position. To study the problems and issues of the public transportation system, Qasimabad, Hyderabad is selected as a study area due to some serious issues of public transportation. Personal observations and questionnaires were used to gather data from the research area. And for analyzing the data SPSS and MS Excel are used. The results reveal that the existing public transportation system is not meeting the needs of residents. Hence use of private transportation is high and causing environmental and traffic jam problems. As $68 \%$ of respondents use a motorbike for recreational purposes, $64 \%$ of respondents are not using public transport due to safety factors. In general, 54\% of respondents were not satisfied with the service of public transport. As people are willing to use public transport but due to some factors such as safety, they are not using public transport so it is suggested that both vehicles and roads must be safe for users. This study aims to study the existing scenario of public transportation in terms of services and facilities, and people's perception about public transportation. So it is concluded that people are tending to use public transport but under some certain conditions (factors preventing the use of public transport), if these concerns are solved then public transport system will become more efficient.
\end{abstract}

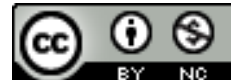

Keywords: Sustainable Transportation, SPSS, Private Vehicles, Public Transportation

\section{Introduction}

The impact of transportation on the dynamic social and economic development of cities and regions is significant (Memon, Madzlan, Talpur, Hakro, \& Chandio, 2014). The quantity and efficiency of transportation networks affect the feasibility and significance of metropolitan areas (Memon, Napiah, Talpur, \& Hakro, 2016). The active transport system provided in a region, naturally, does not cost any money for the smooth movement of persons and goods. Cities today face various obstacles, all of which derive from the transit infrastructure itself and serve as impediments to delivering reliable transportation while simultaneously maintaining a high quality of life (Zavitsas, Kaparias, Bell, \& Tomassini, 2010). Cities are spots that close together with numerous people and activities (Memon, Napiah, Hussain, \& Hakro, 2016). This creates a significant level of accessibility through the provision of diversified travel options and the reduction in travel costs between activities. For example, city dwellers often have more resources and employment in a five-minute walk than in a five-minute drive from suburban and rural areas (Brohi, Brohi, Zehri, \& Rodini, 2020). This maximizes accessibility to economic and social resources for city dwellers (S. Brohi et al., 2020; Litman, 2013).

Planning and investing strategically in infrastructure for sustainable urban transportation is one of the most difficult challenges. People need transportation to get to school, stores, employment, entertainment, health care, and other essential resources, and transportation plays a vital role in community growth (MEMON, 2018). Improved mobility for the poor and disadvantaged groups, especially in developing-world cities, is one of the most significant preconditions for achieving the Millennium Development Goals (Gill, Kalwar, \& Memon, 2021). Cities with interconnected transportation modes are more likely to flourish and flourish as exchange, finance, industry,

\footnotetext{
* Department of City and Regional Planning, Mehran University of Engineering and Technology Jamshoro, Sindh, Pakistan. 76062

** Hanyang University Seoul, South Korea

*** Department of City and Regional Planning, Mehran University of Engineering and Technology Jamshoro, Sindh, Pakistan. 76062
} 
education, tourism, and service centers (Shaikh, Memon, Memon, Laghari, \& Memon, 2020). Cities that consistently rank first in polls of local quality of life include high-quality urban transportation networks that emphasize public transportation and non-motorized modes (Pardo, Jiemian, Hongyuan, \& Mohanty, 2010).

A better knowledge of public transportation will aid in determining the functions of the public and private sectors, as well as identifying the critical government position (Glover, 2011). For the most part, the word "public transportation" refers to the provision of motorized transportation by governments, private citizens, and companies to the general public when these means of transportation became accessible during the middle and late stages of the Industrial Revolution (Kalwar, Memon, \& Qureshi, 2021). As a result, the term "public transportation" has come to mean any transportation service that is accessible to the general public. The notion of public transit became closely correlated with transportation facilities provided or regulated by governments at the local, provincial, federal, interstate, and national scales during the growth of urban and regional transport, and as states started to play a major role in planning modern transport networks involving motorized transport in the late nineteenth century (Glover, 2011).
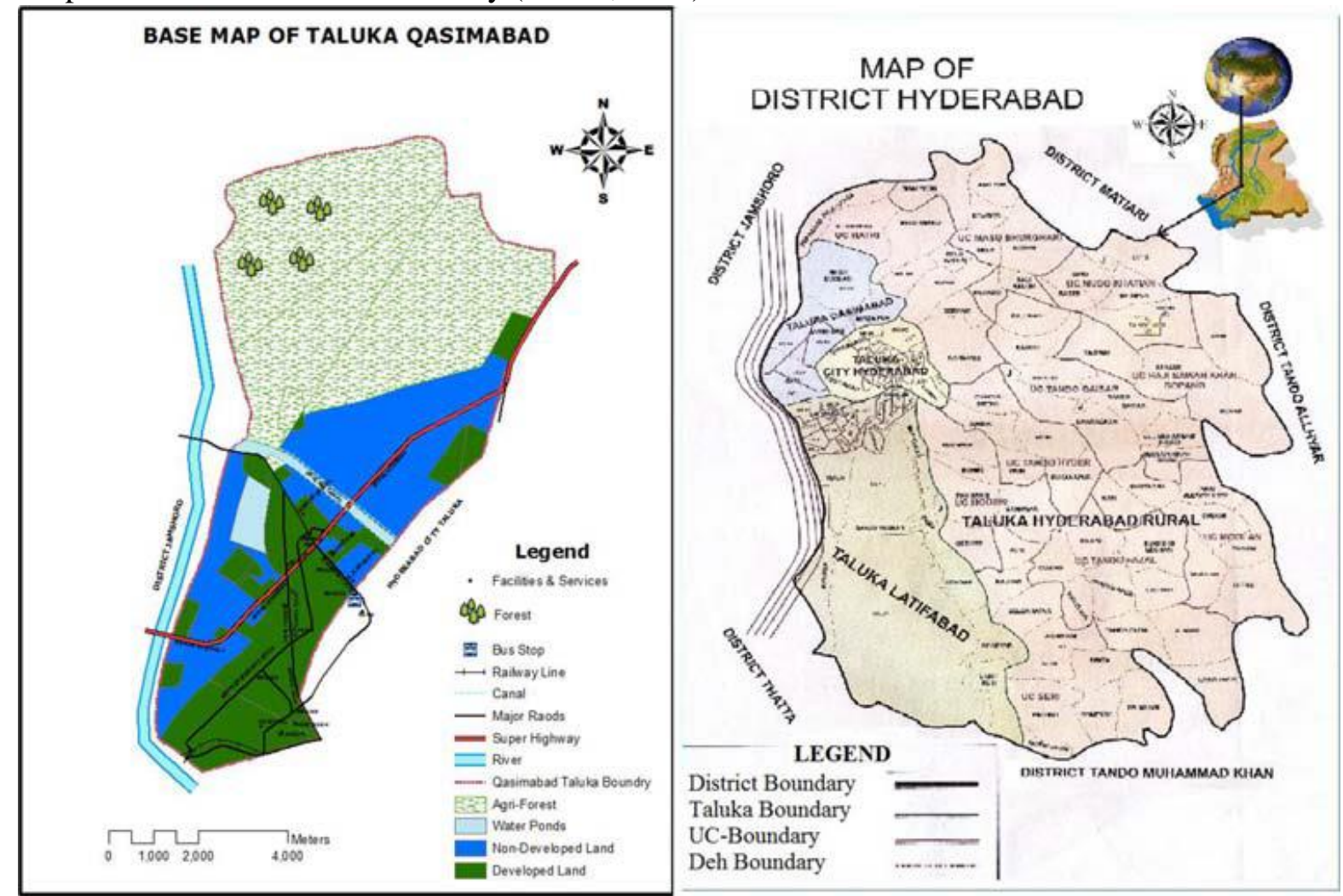

(Mangi, Chandio, Shaikh, \& Talpur, 2018)

Figure: 1 Show the map of the study area

\section{Literature review}

One of the most important ways to alleviate traffic congestion is to develop public transportation networks (Li, Chen, $\mathrm{Li}, \&$ Guo, 2013). Improved public transportation services are needed not only to provide improved public service but also to minimize the demand for personal cars and to mitigate the myriad issues that rapid motorization in a heavily populated country has caused (Wan, Wang, \& Sperling, 2013). The economy of a country is based on public transportation. It provides everyday mobility and connections between people and their careers, schooling, and entertainment from cities to small towns and anywhere in between. As a result, accessibility and simplicity determine the standard of public transportation systems and help to foster a favorable attitude toward them (Aziz \& Amin, 2012).

Commuters' origin and destination points must be near public transportation stations. Ideally, both home and office can be within 500 meters of each other. Only road-based networks are capable of doing so. On average, rail-based networks incorporate another 200-300 meters of walking inside stations, like stairwells. This decreases the approval of rail-based systems concerning surface bus systems, especially among children, the elderly, people with health issues (heart disease, arthritis, 
etc.), and physically disabled people. On every given day, the latter group will make up 20-30\% of the population. Public transit is non-existent in all developing nations, but there are variations between countries and cities. More notably, a shortage of financial resources inhibits investments needed to retain and upgrade existing bus and rail networks, as well as to create new ones. Similarly, many new technologies that have been possible in Western Europe for a long time are mostly out of reach for the majority of developing countries. In the Third World, public transit suffers from widespread mismanagement and corruption, overcrowding and inadequate service, clogged highways that delay buses, and a job environment that is frequently chaotic and completely unorganized (Memon, Kalwar, Sahito, Qureshi, \& Memon, 2020). These problems with public transit emerge in the context of greater mass transportation practices.

Residents are so poor that even low fares are out of reach, and roads aren't intended to serve the poor in the first place. As a result, the poor in developed countries suffer from low mobility and accessibility, especially to work, even more than those in the Western World (Pucher, Korattyswaroopam, \& Ittyerah, 2004). After the energy sector, transportation is the second-largest emitter of carbon dioxide. The automotive industry is still inextricably tied to diesel subsidies. Fuel quality improvements would reduce the economic cost of the fuel subsidy (Yahaya, et al). Cities and regional centers are hubs of operation, necessitating the efficient and easy movement of people and products.

Transportation is always referred to as a city's lifeblood. Because of the high density of operations, high-capacity vehicles including bus, light rail, and subway can be used and they're more affordable, energy-efficient, and take up minimal space than private vehicles. Furthermore, mass transit is available to all, while private vehicles are only available to people that own and can ride them. As a result, cities need as well as an advantage from public transit systems that provide greater mobility for the entire society. Transit services are often required in urbanized environments to allow for a dense population of distinct characteristics, such as homes, corporate offices, warehouses, stadiums, and so on while keeping communities livable and appealing to residents. Self, for-hire, and public transportation (also known as mass transit) are the three types of urban transportation (Vuchic, 2002). Cities and regions' spatial and economic growth is heavily influenced by transportation. The attractiveness and desirability of metropolitan areas were influenced by the quantity and efficiency of transportation facilities. Providing a reliable transit infrastructure in a city to allow for seamless mobility of people and goods does not come cheaply. Cities today face a slew of issues, all of which derive from the transportation infrastructure itself and function as roadblocks to delivering reliable transportation while maintaining a high quality of life (Zavitsas et al., 2010).

Even In the USA, The number of trips taken by Americans on public transportation in 2013 was 10.7 billion, the largest number since the 1950s when few people had cars. $40 \%$ reduction in dependence on imported oil if one out of every ten Americans used public transit regularly. 7: The percentage of days driving in your car is better than using the subway. 450: Millions of gallons saved per year by those who use public transit. This is about the amount of energy used to fuel $14 \%$ of all American homes every year. 6,000: The disparity between a diesel school bus and a natural gas school bus in terms of global warming emissions. $20 \%$ of the total: If one in every five Americans used public transit regularly, the reduction in carbon monoxide pollution will be higher than the total emissions from both chemical refining and metal production sectors (Manon, n.d).

In general, China's public transit infrastructure is subpar, and major issues exist in the public transportation systems of major cities such as Beijing. For example, the passenger load rate is comparatively low during the off-peak period due to the high frequency, while during the peak period, passengers' waiting times are relatively long, with constant bunching and low speed (Nguyen, Han, \& Sahito, 2019). As a result, effectively measuring and assessing public transportation operations, as well as resolving established core challenges, are critical topics that benefit the preparation, construction, and service of the public transportation system. The above issues have prompted studies into the assessment of public transit activities (Jiabin Li., et al.2013).

\section{Research Methodology}

Personal visits, interviews, questionnaires, and field assessments are all part of the suggested research approach. Personal observations and questionnaires were used to survey the research area and gather data (Manzoor, Wei, \& Sahito, 2021; Sahito et al., 2020). The emphasis was placed on gathering a wide range of data that could be combined to solve the research area's challenges and serve as a basis 
for future planning studies. In this analysis, both methods are used to gather data, and SPSS and MS Excel are used to analyze the data.

\section{Research Findings}

The study of data and discussions on the outcomes obtained from the distribution of the questionnaire is seen in this section. Data review is a step that is carried out after the data collection process. In this section, the methods of study, frequency distribution, and results will be presented using Statistical Package Social Science (SPSS) software. Discus is the performance of the questionnaire obtained (Han, Sahito, Thi Nguyen, Hwang, \& Asif, 2019).

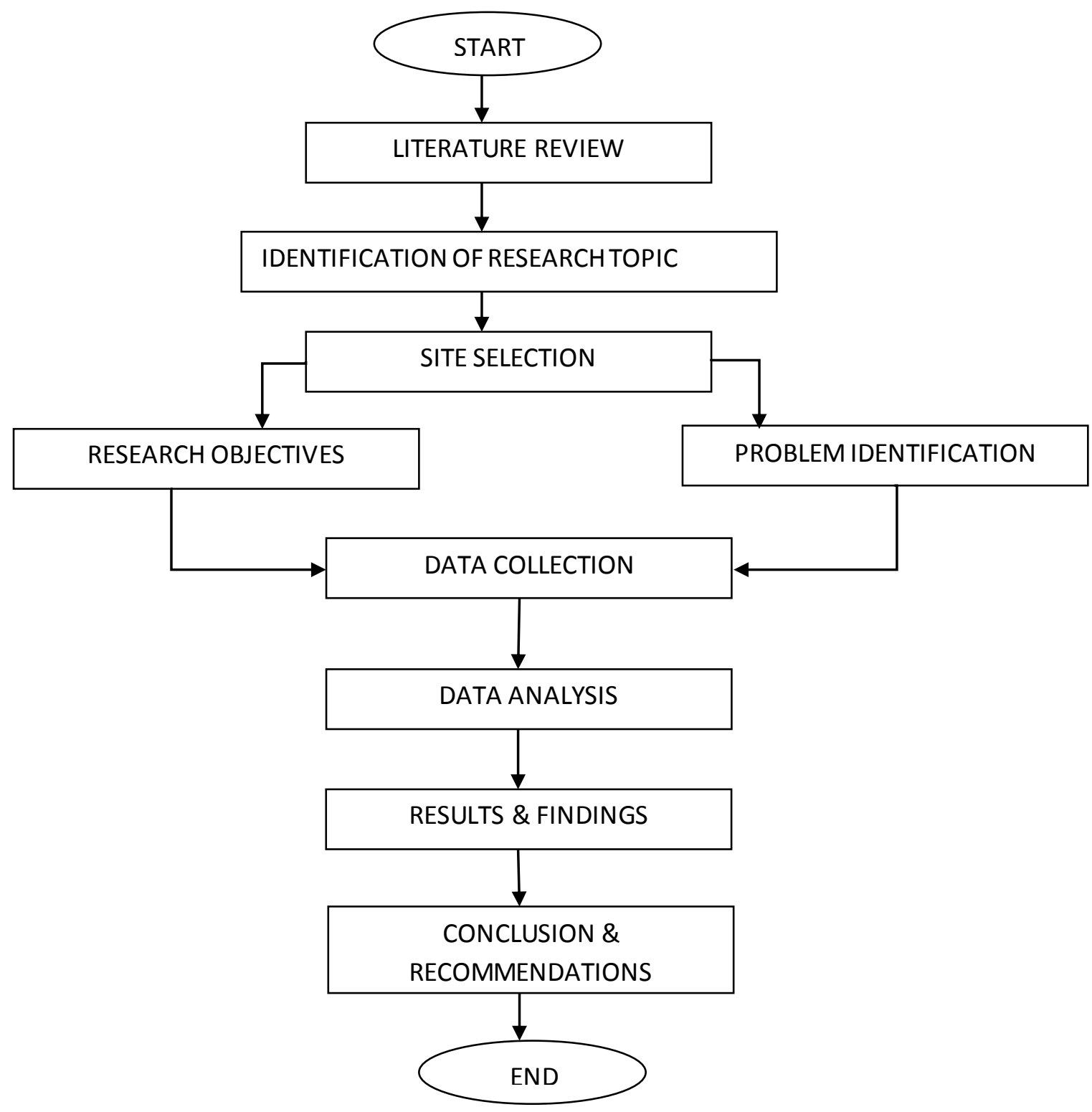

Descriptive Statistics

Figure: 3 Research Process Flow Chart

Descriptive statistics are used to describe the essential characteristics of data in a survey. They have easy-to-understand summaries of the sample and measures. They are the foundation for almost all quantitative data processing, as well as basic graphic analysis Gravetter, F. J., \& Wallnau, L. B. (2000).

\section{Results}

The results of our article are given below. The data were collected and analyzed using SPSS software.

\section{Demographic Information of Respondents}

A questionnaire was designed to get responses from riders of transportation. The questionnaire was disturbed, male gave more responses while filling the questionnaires. 


\begin{tabular}{ll}
\hline Table 1: Frequency and Percentage of Gender & \\
\hline Gender & Percentage $(\%)$ \\
\hline Male & 58 \\
Female & 42 \\
Total & 100.0 \\
\hline
\end{tabular}

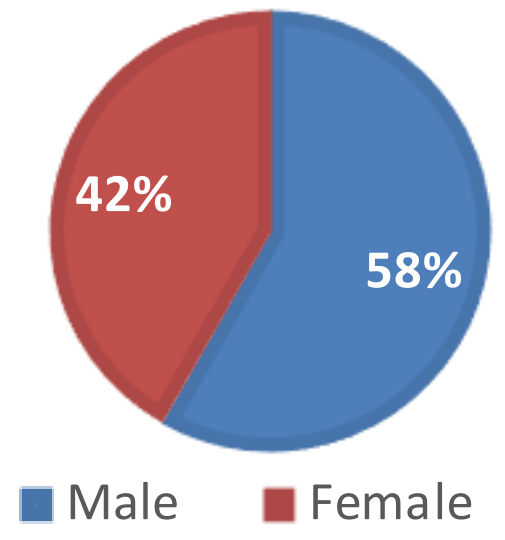

Figure 2: Gender

The frequency and sex ratio of the respondents in the sample are shown in Table 1 and Figure 1. $58 \%$ of respondents were male and $42 \%$ were female

Table 2 Frequency and Percentage of Age

\begin{tabular}{ll}
\hline Age & Percentage (\%) \\
\hline $15-20$ & 7 \\
$21-25$ & 14 \\
$26-30$ & 41 \\
$31-35$ & 21 \\
$36-40$ & 17 \\
Total & 100.0 \\
\hline
\end{tabular}

The frequency and age ratio of the respondents are shown in table 2 The age of respondents is based on the age of young people 15 and over. Regarding the pie map, with a proportion of 27.5 percent, most respondents are between the ages of 26-30 years. Meanwhile, 25.6\% of participants are between the ages of 26 and 30. At 22.5 percent, the respondents were between 31 and 35 years old. Participants increased by 17.6 percent from 36 to 40 years old. Finally, from 15 to 20 years of age, only 6.8 percent of respondents participated in this research.

\section{Mode of Transport}

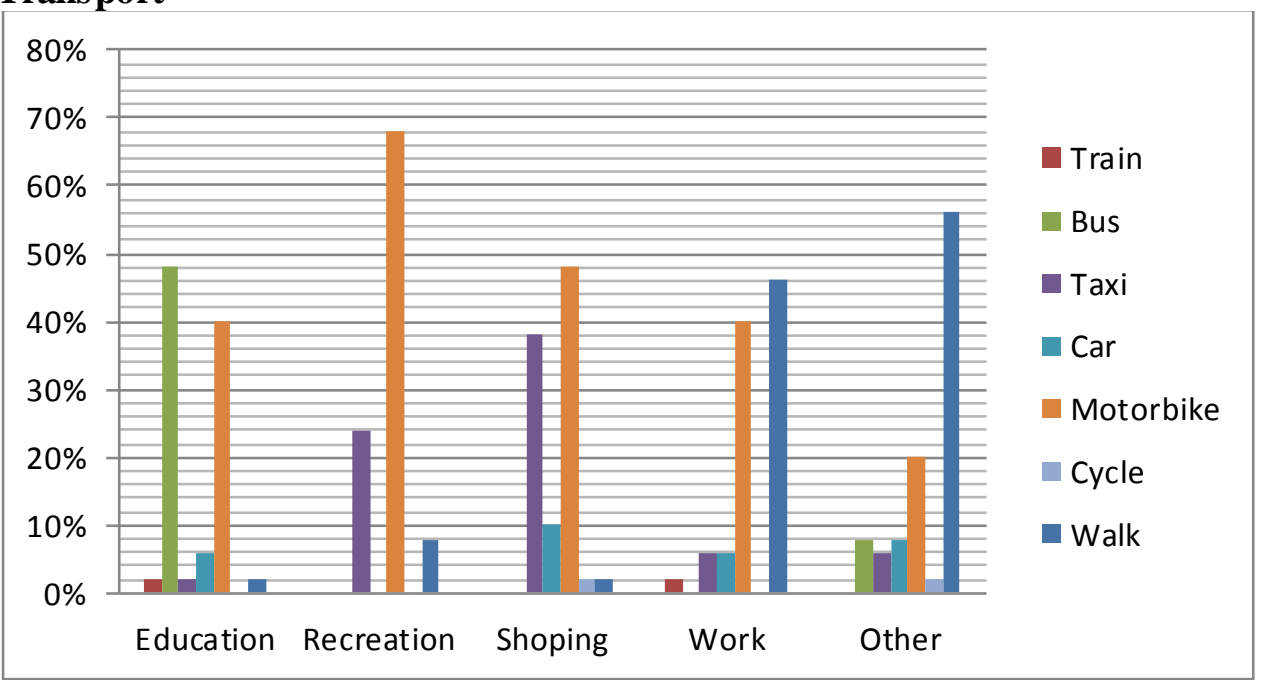

Figure 3 Usage of a different mode of transport for different purposes

Figure 3 shows the usage of a different mode of transport (Train, Bus/Suzuki, Taxi, Car, Motorbike, Cycle, walk) for different purposes (Education, Recreation, Shopping, Work, Other). According to this, $48 \%$ of people use Bus/Suzuki for educational purposes, $68 \%$ people use a 
motorbike for recreational purposes, $48 \%$ people use a motorbike for shopping purposes, $46 \%$ people go to work by walk.

\section{Factors preventing the use of public trans port}

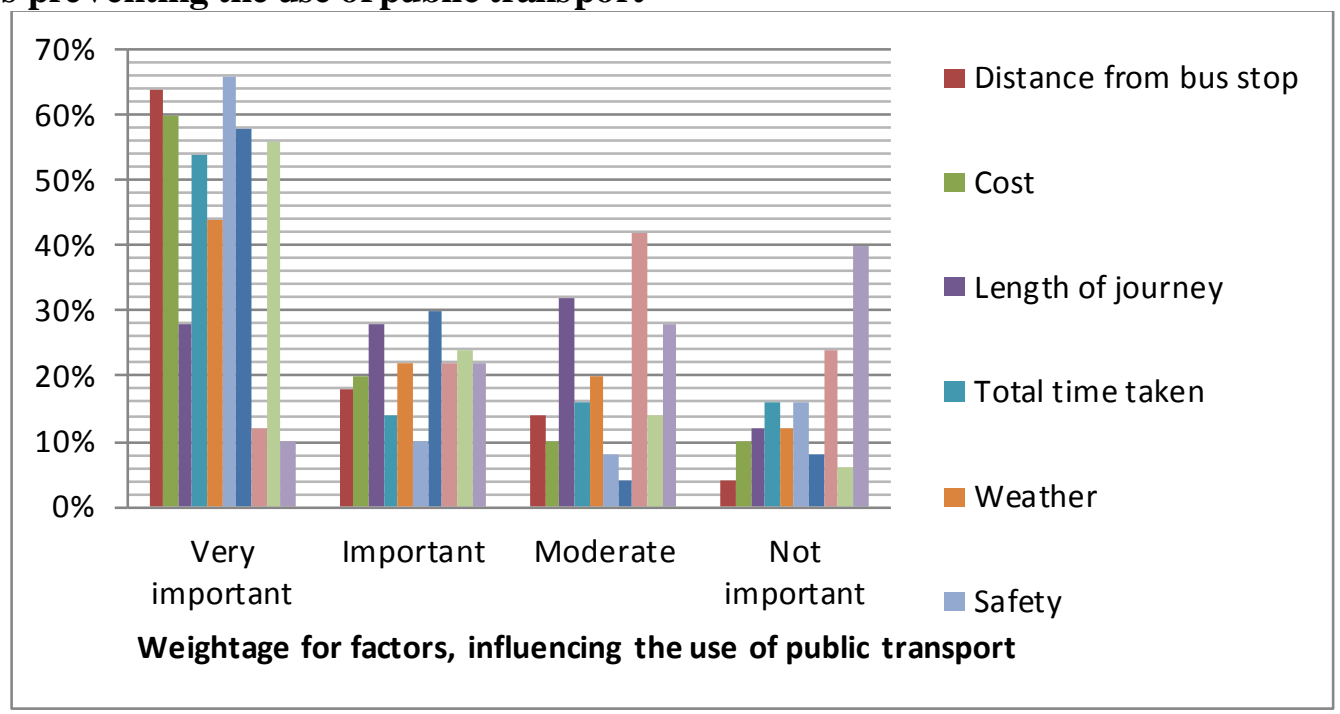

Figure 4 the factors preventing to use of public transport.

Figure 4 is representing the views of people regarding the factors which are caused to prevent to use of public transport. According to this table, 64\% people said that safety is a very important factor to prevent the use of public transport, $30 \%$ people said that lack of available information regarding public transport is an as important factor to prevent the use of public transport, $42 \%$ people said that poor frequency of service is a moderate factor to prevent the use of public transport.

Availability of fle xible schedule of public trans port

Table 3 Availability of more flexible schedule of public transport.

\begin{tabular}{lll}
\hline S.NO & Availability of flexible schedule & Frequency \\
\hline 01 & Yes & 40 \\
02 & No & 28 \\
03 & Not sure & 32 \\
\hline
\end{tabular}

Table 3 shows that how many people have a more flexible schedule to use public transport easily. According to this table, $40 \%$ of people have a more flexible schedule, $28 \%$ of people don't have a flexible schedule and $32 \%$ are not sure about a flexible schedule it means sometimes they have and sometimes don't.

\section{Satisfaction with public transport}

Table 4 Satisfaction with service of Public Transport

\begin{tabular}{ccc}
\hline S.NO & Satisfaction with service of public transport & Percent \\
\hline 01 & Yes & 52.0 \\
02 & No & 46.0 \\
\hline
\end{tabular}

Table 4 indicates the level of satisfaction of public transportation services. According to this table, 54 percent of respondents were dissatisfied with public transportation service, while 46 percent were satisfied.

\section{Travel Time to Reach Destination}

The travel time to reach the destination by using public transport is shown in table 5. The results show that 75 commuters responded that, public transport took 30-60 minutes to reach the destination, while, remaining replied that public transport took 05-15 minutes to reach the destination. However, most of the commuters replied that public transport takes too much time to reach the destination as compared to own a vehicle.

Table 5 Time taken to reach the destination

\begin{tabular}{ll}
\hline Variable & No Responded \\
\hline $5-10$ minutes & 04 \\
$10-15$ minutes & 11 \\
$15-30$ minutes & 41 \\
$30-60$ minutes & 34 \\
Total & 90 \\
\hline
\end{tabular}


As a result, an increase in the number of private cars triggers signif icant urban environmental concerns such as road congestion, air emissions, and noise pollution.

\section{Corre lation statistical}

The correlation statistical test was used to check the reliability of variables like time travel per day and time take to reach the destination.

Table 6 Correlation between time travel per day and time is taken to reach the destination

\begin{tabular}{llll}
\hline & & Travel time & $\begin{array}{l}\text { Time is taken to } \\
\text { reach destination }\end{array}$ \\
\hline Travel time & Pearson Correlation & 1 & $-.101^{*}$ \\
& Sig. (2-tailed) & & .049 \\
& $\mathrm{~N}$ & 90 & 90 \\
Mode of Transport. & Pearson Correlation & $-.101^{*}$ & 1 \\
& Sig. (2-tailed) & .049 & \\
& $\mathrm{~N}$ & 90 & 90 \\
\hline & $*$ Correlation is significant at the 0.05 level (2-tailed).
\end{tabular}

The correlation test shows a significant negative relationship between travel time and mode of transport, $\mathrm{r}=-.101, \mathrm{p}<.01$. As results show a negative relationship between variables. It means when vehicles take more time to reach their destination, commuters will look for their vehicles. So, travel time plays an important role.

Car ownership is a big issue in developing countries. However, the poor service (condition of vehicles and roads, time delay, accessibility, improper timing, etc.) of public transport compels residents to move on their vehicles. Results revealed that $80 \%$ of people are not satisfied with the quality of public transport. Results found that 67 respondents use their vehicles. Commuters have no other option as correlation showed that when public transport take more travel time to reach the destination, they look for another mode of transport, hence car ownership increase. Resultantly, traffic congestion, environmental degradation, energy consumption takes place. If the public transport is efficient, adequate, affordable, time-saving, with trained staff is provided in the study area. The commuters will shift from personal motor vehicles to adequate public transport.

\section{Conclusions}

Cities are densely populated areas with a high density of inhabitants and services. This offers a high degree of connectivity; i. e., by offering a variety of transportation solutions and shortening the lengths between operations, they aim to minimize transportation costs. For example, city dwellers often have more facilities and employment within a five-minute walk than inhabitants in suburbs have within a five-minute drive. This increases access to financial and other resources for city dwellers. People need transportation to get to school, stores, employment, entertainment, health care, and other important resources, and transportation plays a critical role in community growth. Improved mobility for the poor and disadvantaged groups, especially in developing-world cities, is one of the most significant preconditions for achieving the Millennium Development Goals. Recognizing what comprises public transportation will help to clarify the positions of public and private transportation and alleviate some of the uncertainty caused by attempts to use private transportation forms to fix public transportation issues.

As it is found that people are willing to use public transport but due to some factors such as safety, they are not using public transport so it is suggested that both vehicles and roads must be safe for users. To encourage the use of public transport the higher parking charges must be charged from private transport users. As public transport is highly used for educational purposes so there must be a separate service for students which may reduce their travel time and as well as cost.

\section{Recommendations}

As it is found that people are willing to use public transport but due to some factors such:

- $\quad$ For safety, they are not using public transport so it is suggested that both vehicles and roads must be safe for users.

- $\quad$ To encourage the use of public transport the higher parking charges must be charged from private transport users. As public transport is highly used for educational purposes so there must be a separate service for students which may reduce their travel time and as well as cost. New buses/minibusses should be used to ensure a safe and comfortable public transport service. 
References

Aziz, A., \& Amin, N. F. M. (2012). Transforming the land public transport system in Malaysia. Sharing Urban Transport Solutions, 30.

Brohi, S., Brohi, A. A., Zehri, A. W., \& Rodini, Y. A. (2020). Identify The Problems and Satisfaction Level of the Hostel Students Concerning Basic Facilities at University of Sindh Jamshoro Pakistan. Pakistan Studies (Bi-Annual), 11(01), 43-55.

Brohi, S., Khuhro, T. A., Kalwar, S., Brohi, A. A., Brohi, Y. K., \& Rajput, A. A. (2020). Assessment of agriculture sector using SWOT analysis: A case study of Mirpur Khas, Sindh. Sindh University Research Journal-SURJ (Science Series), 52(04), 369-374. doi: 10.26692/sujo/2020.12.55

Gill, R., Kalwar, S., \& Memon, I. A. (2021). Yeh's Satisfaction Index Modelling of Tenants in Rental Appartments (A Case Study of Latifabad Hyderabad). Sukkur IBA Journal of Computing and Mathematical Sciences(2), 1-10\% V 14. doi: 10.30537/sjcms.v4i2.654

Glover, L. (2011). Public transport as a common pool resource.

Han, H., Sahito, N., Thi Nguyen, T. V., Hwang, J., \& Asif, M. (2019). Exploring the features of sustainable urban form and the factors that provoke shoppers towards shopping malls. Sustainability, 11(17), 4798.

Kalwar, S., Memon, I. A., \& Qureshi, S. (2021). Significance of National Spatial Planning for Economic Development of Secondary Cities in India: Critical Analysis of JNNURM Programme. Sukkur IBA Journal of Computing and Mathematical Sciences(2), 49-60\%V 44. doi: $10.30537 /$ sjems.v4i2.658

Li, J., Chen, X., Li, X., \& Guo, X. (2013). Evaluation of public transportation operation based on data envelopment analysis. Procedia-Social and Behavioral Sciences, 96, 148-155.

Litman, T. (2013). Smarter congestion relief in Asian cities. Transport and Communications Bulletin for Asia and the Pacific, 82(1).

Mangi, M. Y., Chandio, I. A., Shaikh, F. A., \& Talpur, M. A. h. (2018). Urban land-use planning trend and sustainable challenges in socio-economic development. Mehran University Research Journal of Engineering \& Technology, 37(2), 397-404.

Manzoor, F., Wei, L., \& Sahito, N. (2021). The role of SMEs in rural development: Access of SMEs to finance as a mediator. Plos one, 16(3), e0247598.

MEMON, I. A. (2018). Mode Choice Modelling to Shift Car Travelers Towards Park and Ride Service in the CBD of Putrajaya and Karachi. (Ph.D.), Universiti Teknologi PETRONAS. Retrieved from http://utpedia.utp.edu.my/id/eprint/18372

Memon, I. A., Kalwar, S., Sahito, N., Qureshi, S., \& Memon, N. (2020). Average Index Modelling of Campus Safety and Walkability: The Case Study of the University of Sindh. Sukkur IBA Journal of Computing and Mathematical Sciences(1), 37-44\% V 34. doi: 10.30537/sjcms.v4i1.582

Memon, I. A., Madzlan, N., Talpur, M. A. H., Hakro, M. R., \& Chandio, I. A. (2014). A review on the factors influencing the Park-and-Ride traffic management method. Paper presented at the Applied Mechanics and Materials.

Memon, I. A., Napiah, M., Hussain, M. A., \& Hakro, M. R. (2016). Influence of factors to shift private transport users to Park-and-Ride service in Putrajaya. Paper presented at the In Engineering Challenges for Sustainable Future: Proceedings of the 3rd International Conference on Civil, Offshore and Environmental Engineering (ICCOEE 2016, Malaysia, 1517 Aug 2016).

Memon, I. A., Napiah, M., Talpur, M. A. H., \& Hakro, M. R. (2016). Mode choice modeling method to shift car travelers towards Park and Ride service. ARPN Journal of Engineering and Applied Sciences, 11(6), 3677-3683.

Nguyen, T. V. T., Han, H., \& Sahito, N. (2019). Role of urban public space and the surrounding environment in promoting sustainable development from the lens of social media. Sustainability, $11(21), 5967$.

Pardo, C. F., Jiemian, Y., Hongyuan, Y., \& Mohanty, C. R. (2010). Shanghai manual: A guide for sustainable urban development in the 21st century. Sustainable Urban Transport, 38.

Pucher, J., Korattyswaroopam, N., \& Ittyerah, N. (2004). The crisis of public transport in India: overwhelming needs but limited resources. Journal of public transportation, 7(4), 1. 
Sahito, N., Han, H., Nguyen, T. V. T., Kim, I., Hwang, J., \& Jameel, A. (2020). Examining the QuasiPublic Spaces in Commercial Complexes. Sustainability, 12(5), 1830.

Shaikh, K., Memon, A., Memon, I. A., Laghari, Z. A., \& Memon, A. M. (2020). Awareness regarding Coronavirus pandemic among the population of Sindh, Pakistan: A cross-sectional study. Sukkur IBA Journal of Computing and Mathematical Sciences(1), 28-36\% V 24. doi: 10.30537/sjcms.v4i1.573

Vuchic, V. R. (2002). Urban public transportation systems. University of Pennsylvania, Philadelphia, PA, USA, 5, 2532-2558.

Wan, Z., Wang, X., \& Sperling, D. (2013). Policy and politics behind the public transportation systems of China's medium-sized cities: Evidence from the Huizhou reform. Utilities Policy, $27,1-8$.

Zavitsas, K., Kaparias, I., Bell, M. G., \& Tomassini, M. (2010). Transport problems in cities. CONDUITS Deliverable, 1 . 